\title{
Oral flunarizine versus oral amitriptyline in migraine prophylaxis - A prospective open label study
}

\author{
Bhavani $\mathrm{V}^{1}$, Nagabushan $\mathrm{H}^{2 *}$, Bhagyavathi H. $\mathrm{D}^{3}$ \\ ${ }^{1}$ PG Tutor, ${ }^{2}$ Professor and HOD, ${ }^{3}$ Associate Professor, ${ }^{1,2}$ Dept. of Pharmacology, ${ }^{3}$ Dept. of Psychiatry, Mandya Institute of Medical \\ Sciences, Mandya, Karnataka, India \\ *Corresponding Author: Nagabushan H \\ Email: bushan123@rediffmail.com
}

\begin{abstract}
Objectives: To compare the effectiveness and tolerability of flunarizine and amitriptyline in migraine prophylaxis. Also to assess the disability associated with migraine using Migraine Disability Assessment Test (MIDAS) and Headache Impact Test-6 (HIT-6) questionnaires.

Materials and Methods: The study was a prospective observational, open-label, comparative study, conducted for six months among migraine patients attending Tertiary Care Hospital, Mandya. Patients were prescribed either Amitriptyline 25 mg or flunarizine 10 mg OD for three months. Effectiveness was assessed by the number of episodes of migraine attacks, pain severity score on Visual Analogue Scale (VAS), tolerability of adverse reactions reported and disability assessed using MIDAS and HIT-6 questionnaires.

Results: Out of 103 patients, 55 were prescribed Amitriptyline and 48 patients flunarizine. $49.5 \%$ of patients were between 18 to 30 years of age. At the end of three months of treatment, the frequency and severity of headaches decreased from baseline in both the groups. The overall percentage of responders with $\geq 50 \%$ reduction from baseline in number of migraine episodes and pain severity together were $67.3 \%$ and $50 \%$ in amitriptyline and flunarizine groups respectively. There was reduction in MIDAS and HIT-6 scores in both groups, without significant difference between the groups. Both the drugs were well tolerated, with most common adverse effects being dry mouth, somnolence, and constipation.

Conclusion: Both amitriptyline and flunarizine are effective in prophylaxis of migraine, with significant reduction in number of episodes and severity of headache from baseline to end of treatment. However, Amitriptyline had a higher overall responder rate when compared to Flunarizine, with similar tolerability profile.
\end{abstract}

Keywords: Migraine prophylaxis, Amitriptyline, Flunarizine, MIDAS, HIT-6.

\section{Introduction}

Headache disorders are one of the most common disorders involving the nervous system. The characteristic features of headache disorders are mainly recurrent headache, pain and disability which impair the quality of life and increase the financial burden. Approximately half of the adults in the world are estimated to have a symptomatic headache at least once within a year and at least $30 \%$ or more among them have reported a migraine. ${ }^{1}$

Tension-type headache and migraine are the second and third most prevalent disorders in the world (after dental caries). ${ }^{2}$ Migraine was ranked seventh highest among specific causes of disability globally, responsible for $2.9 \%$ of all years of life lost to disability (YLDs). ${ }^{3}$

To diagnose migraine, there should be recurrent or repeated attacks of headache which usually is pulsatile, last for 4 to $72 \mathrm{hrs}$, unilateral (but not always), moderate to severe in intensity, and associated with or without aura, nausea, vomiting, photophobia and phonophobia. ${ }^{4}$ These headaches can worsen with routine physical activity. ${ }^{5}$ Migraine is more common in females than in males by a factor of 2:1, probably because of hormonal influences. ${ }^{1}$ It is a chronic illness which can occur at all ages; however, the highest prevalence is seen between 35 to 45 years of age. ${ }^{6}$

Prophylactic drugs which are most commonly used for the treatment of migraine with good efficacy and tolerability are beta blockers, calcium channel blockers, antidepressants, anti-epileptic drugs and miscellaneous drugs. ${ }^{7}$ The goal of prophylactic treatment should be to prevent or reduce the frequency of migraine attacks, shorten the duration of headaches, reduce their severity, improve response to acute medications, improve patient function and to reduce disability. The non-specific calcium channel blocker flunarizine which is among the drugs of first choice for the prophylactic therapy has been shown to be effective in a dose of 5-10 $\mathrm{mg}$ in migraine prophylaxis in several studies. The tricyclic antidepressant with consistent efficacy in migraine prophylaxis is amitriptyline in doses between 10 and $150 \mathrm{mg}$. Previous studies have shown positive results and it is one among the drugs of second choice for migraine prophylaxis. $^{8}$

A migraine prophylaxis is regarded as successful if the frequency of migraine attacks per month is decreased by at least $50 \%$ within 3 months. ${ }^{8}$ Not many studies have been conducted to compare the effectiveness of flunarizine and amitriptyline. Hence, this study was undertaken to compare the effectiveness and tolerability of flunarizine and amitriptyline as monotherapy in the prophylaxis of migraine.

\section{Objectives}

1. To compare the effectiveness and tolerability of flunarizine and amitriptyline in migraine prophylaxis.

2. To assess the disability associated with migraine using Migraine Disability Assessment Test (MIDAS) and Headache Impact Test-6 (HIT-6) questionnaires. 


\section{Materials and Methods}

This study was a prospective observational, open-label, comparative study. The study was conducted for a period of six months from December 2017 to May 2018, after obtaining Institutional Ethics Committee approval. Patients with migraine attending department of Psychiatry, MIMS, Mandya, were enrolled based on inclusion and exclusion criteria after obtaining written informed consent. Patients were recruited in the first three months and were followed up for three months.

\section{Inclusion Criteria}

1. Patients between the ages of 18 to 60 years of both sexes diagnosed with migraine and prescribed prophylactic drug with either of the study medications.

\section{Exclusion Criteria}

1. Patients $<18$ and $>60$ years of age.

2. Patients allergic to study medication.

3. Use of prophylactic medication 3 months prior to inclusion.

4. All other primary headaches (tension type, cluster headache etc) and secondary headaches.

5. Pregnant and lactating women.

6. Any significant CVS, CNS, hepatic, renal or respiratory dysfunction.

7. Patients with major psychiatric illness undergoing treatment.

8. Patients not giving consent.

\section{Method of Data Collection}

1. Data regarding patients' age, sex, weight, MIDAS $^{9}$ and HIT- $6^{10}$ scores, medication prescribed to the patient, etc were collected.

2. Patients received either tablet Flunarizine $10 \mathrm{mg}(\mathrm{n}=48)$ or tablet Amitriptyline $25 \mathrm{mg}(\mathrm{n}=55)$ once daily at night for a duration of three months.

3. All the patients were provided with a migraine diary and advised to record the number of attacks of migraine, its severity or intensity using Visual Analogue Scale (VAS), duration and any adverse events. Patients were also prescribed rescue analgesic if necessary by the treating psychiatrist to control the acute attacks.

4. Patients were followed-up at the end of $1^{\text {st }}$ and $3^{\text {rd }}$ month after starting the prophylaxis. During the followup the migraine diary was checked to ascertain the change in the migraine frequency and pain intensity.

5. HIT-6 score and weight were assessed and recorded at the baseline, end of $1^{\text {st }}$ month and at the end of $3^{\text {rd }}$ month of follow up. MIDAS score was assessed and recorded at the baseline and at the end of $3^{\text {rd }}$ month of follow up.

6. Tolerability of the drug was assessed based on adverse drug reactions.

7. Number of patients with adverse events and the number of patients withdrawn due to adverse events were considered the primary outcome of tolerability.

\section{Outcome Measure}

1. Mean reduction in migraine frequency, headache days (which includes all the days patients experienced a headache irrespective of the number of migraine attacks) and pain severity at $1^{\text {st }}$ and $3^{\text {rd }}$ month.

2. Overall percentage responders, i.e., more than $50 \%$ reduction in migraine frequency and pain severity at the end of 3 months.

3. Changes in weight.

4. Difference in MIDAS and HIT-6 scores.

5. Adverse drug reactions.

\section{Statistical Analysis}

All collected information was entered in excel sheet and analyzed using Statistical Package for Social Sciences version 20 software, 2015. Descriptive statistics, Chi-square test, paired and unpaired-t-test were used.

\section{Results}

Initially 128 patients with history of recurrent headaches were screened of which 117 patients fit into the study criteria. Among them 63 patients were prescribed Amitriptyline and 54 patients were prescribed flunarizine. Two patients from both the groups were excluded from the analysis since they did not start the study medication as per the prescription. Six patients in Amitriptyline group and four patients in flunarizine group were excluded from the analysis, since they stopped the study medication after one month of treatment. The analysis was done for a total of 103 patients (55 in Amitriptyline group and 48 in flunarizine group) who completed the study. (Chart 1: Consort Flow Chart).

Demographic and Baseline Characteristics: Demographic and Baseline characteristics were comparable in both the treatment groups. Most of the patients in this study were between the age group of 18 to 30 years $(n=51,49.5 \%)$, followed by age group 31 to 45 years $(n=46,44.6 \%)$ and 46 to 60 years $(n=6,5.8 \%)$. There were more females $(n=81)$ than males $(n=22)$ in the study groups (Fig. 1). The mean \pm SD weight at baseline was $59.7 \pm 8.9$ and $54.1 \pm 11.1$ kilograms in amitriptyline and flunarizine groups respectively (Table 1).

Headache Characteristics: Majority of the patients had unilateral headache $(\mathrm{n}=42,41 \%)$ (Fig. 2), associated most commonly with nausea $(\mathrm{n}=76,74 \%)$, followed by photophobia $(n=67,65 \%)$, phonophobia $(n=61,59 \%)$ and vomiting ( $\mathrm{n}=50,48 \%)$ (Fig. 3). The patients had a history of migraine headaches for $3.75 \pm 4.4$ and $3.73 \pm 4.3$ years respectively in amitriptyline and flunarizine groups (Table $1)$.

The patients in Amitriptyline group had a mean \pm SD of $26.1 \pm 12.5$ number of episodes with a mean \pm SD of $32.9 \pm 14.1$ number of days with headache in the last 3 months, and a mean \pm SD of $8.44 \pm 1.5$ pain severity score on VAS. The patients in flunarizine group had a mean \pm SD a mean of $29.4 \pm 15.6$ number of episodes with a mean \pm SD of $35.8 \pm 16.9$ number of days with headache in the last 3 months, and \pm SD of $8.42 \pm 1.6$ pain severity score on VAS, with no statistically significant differences between the two groups (Table 1). 
The number (\%) of patients who had worst pain at baseline was $36(34.9 \%)$, severe pain $48(46.6 \%)$, and moderate pain was $19(18.4 \%)$ (Table 2).

The mean \pm SD MIDAS score at baseline was $15.5 \pm 8.1$ and $15.8 \pm 9.1$ in the amitriptyline and flunarizine groups respectively which were not significantly different between the groups $(\mathrm{p}=0.95)$. The mean \pm SD HIT -6 score at baseline was $69.5 \pm 5.3$ and $69.7 \pm 4.4$ in the amitriptyline and flunarizine groups respectively with no statistically significant difference between groups $(\mathrm{p}=0.26)$ (Table 1).

Based on MIDAS score the number (\%) of patients with severe disability were $23(22.3 \%)$, moderate disability $47(45.6 \%)$, mild disability $31(30 \%)$ and little or no disability were $2(1.9 \%)$ at baseline (Fig. 4). The number (\%) of patients with severe and substantial impact were 102 $(99 \%)$ and $1(0.9 \%)$ respectively based on HIT-6 impact score at the baseline (Fig. 5). The most common rescue analgesic prescribed for the patients to control the acute attacks were oral tablets of Naproxen, Paracetamol and Diclofenac.

At follow-up 1: (at the end of one month) (Table 3)

At the end of one month of treatment, the patients were followed up and assessed for the number of episodes, pain severity, weight, and HIT-6 impact scores. The mean \pm SD number of episodes was $7.24 \pm 4.8$ and $9.17 \pm 6.1$ in the amitriptyline and flunarizine groups respectively, which were significantly reduced from baseline with $\mathrm{p}$-value being $<0.01$ in both the groups (Table 5). The percentage reduction from baseline in the number of episodes was $72.2 \%$ in Amitriptyline group and $68.8 \%$ flunarizine group.

The mean \pm SD pain severity score on VAS was $5.87 \pm 2.0$ in the Amitriptyline group and $6.13 \pm 1.6$ in the flunarizine group. There was a significant reduction in the pain scores in both the groups indicated by a p-value of < 0.01 when compared to the baseline (Table 5). The percentage fall in pain score from baseline to the end of one month of treatment was $30.4 \%$ in Amitriptyline group and $27.2 \%$ in flunarizine group.

The number (\%) of patients who had worst pain at the end of one month was $3(2.9 \%)$, severe pain $34(33 \%)$, moderate pain was $59(57.2 \%)$ and mild pain was $7(6.7 \%)$ (Table 2).

The mean \pm SD HIT-6 score was $56.1 \pm 9.1$ in the Amitriptyline group and $55.9 \pm 8.2$ in the flunarizine group with statistically significant reduction when compared to the baseline $(p<0.01$ in both the groups) (Table 5). The percentage fall in HIT-6 score from baseline to the end of one month was $19.2 \%$ in Amitriptyline group and $19.8 \%$ in flunarizine group.

At follow-up 1, the mean \pm SD of weight in kilograms

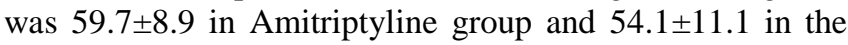
flunarizine group, with no statistically significant difference in comparison to the baseline weight in both the groups ( $\mathrm{p}=1.0$ in both the groups).

There were mild adverse events reported in Amitriptyline group with dry mouth being the most common adverse event. In flunarizine group dry mouth and somnolence were the most common adverse events (Table $6)$.

At follow-up 2: (at the end of three months) (Table 4)

At the end of three months of treatment, the patients were followed up and assessed for the number of episodes, number of days with headache in the last three months, pain severity, weight, and HIT-6 impact and MIDAS scores. The mean \pm SD number of episodes was $4.45 \pm 3.5$ and $4.69 \pm 4.3$ in the amitriptyline and flunarizine groups respectively, which were significantly reduced from baseline with p-value of < 0.01 in both the groups (Table 5). The number (\%) of patients with $\geq 50 \%$ reduction in number of episodes were $55(100 \%)$ in amitriptyline group and $46(95.8 \%)$ in flunarizine group.

The mean \pm SD number of days with headache in the last 3 months was $12.1 \pm 7.8$ in the Amitriptyline group and $13.9 \pm 9.5$ in flunarizine group, which were significantly reduced from baseline with $\mathrm{p}$-value of $<0.01$ in both the groups (Table 5).

The mean \pm SD pain severity score on VAS was $3.73 \pm 2.3$ in the Amitriptyline group and 4.02 \pm 2.1 in flunarizine group, $\mathrm{p}$-value $<0.01$ when compared to the baseline (Table 5). The number $(\%)$ of patients with $\geq 50 \%$ reduction in VAS were $37(67.2 \%)$ in Amitriptyline group and $27(56.2 \%)$ in flunarizine group.

The number (\%) of patients who had worst pain at the end of three months was $1(0.9 \%)$, severe pain $13(12.6 \%)$, moderate pain $40(38.8 \%)$, mild pain $36(34.9 \%)$ and no pain was $13(12.6 \%)$. The number of patients with no pain was slightly higher in the amitriptyline group than in the flunarizine group (Table 2).

The mean \pm SD HIT- 6 impact score was $48.3 \pm 7.8$ in the Amitriptyline group and $48.8 \pm 8.3$ in the flunarizine group with statistically significant reduction in score when compared to the baseline ( $<<0.01$ in both the groups) (Table 5). The percentage fall in HIT-6 score from baseline to the end of three months of treatment was $30.5 \%$ in amitriptyline group and $30 \%$ in flunarizine group.

The number (\%) of patients with severe impact was 10 (9.7\%), substantial impact $11(10.6 \%)$, moderate impact 24 (23.3\%) and little-to-no impact $58(56.3 \%)$ based on HIT-6 impact score (Fig. 5).

The mean \pm SD MIDAS score at follow-up 2 was $5.56 \pm 3.9$ and $6.42 \pm 5.1$ in the amitriptyline and flunarizine groups respectively which were not significantly different between the groups $(p=0.60)$ (Table 4$)$, however, there was a significant reduction $(\mathrm{p}<0.01)$ in the MIDAS scores when compared to the baseline in both the groups (Table 5). The percentage reduction in MIDAS score was $64.3 \%$ in amitriptyline group and $59.4 \%$ in flunarizine group. Based on MIDAS score the number (\%) of patients with severe disability was $1(0.9 \%)$, moderate disability 14 (13.6\%), mild disability $30(29.1 \%)$ and little or no disability was 58 $(56.3 \%)$ at the end of three months (Fig. 4).

The mean \pm SD weight in kilograms at follow-up 2 was $59.6 \pm 8.8$ in amitriptyline group and $54.1 \pm 10.9$ in the flunarizine group. There was no significant difference in the weight at the end of three months when compared to 
baseline in both the groups $(\mathrm{p}=0.22$ and $\mathrm{p}=0.59$ respectively).

In amitriptyline group, dry mouth and somnolence were the most common adverse events followed by constipation. In the flunarizine group dry mouth was the most common adverse event followed by weakness and somnolence (Table $6)$.

The percentage responders, the number $(\%)$ of patients with $\geq 50 \%$ reduction in number of episodes of migraine and severity were $37(67.3 \%)$ and $24(50 \%)$ in amitriptyline and flunarizine groups respectively.

\section{Chart 1: Consort flow chart}

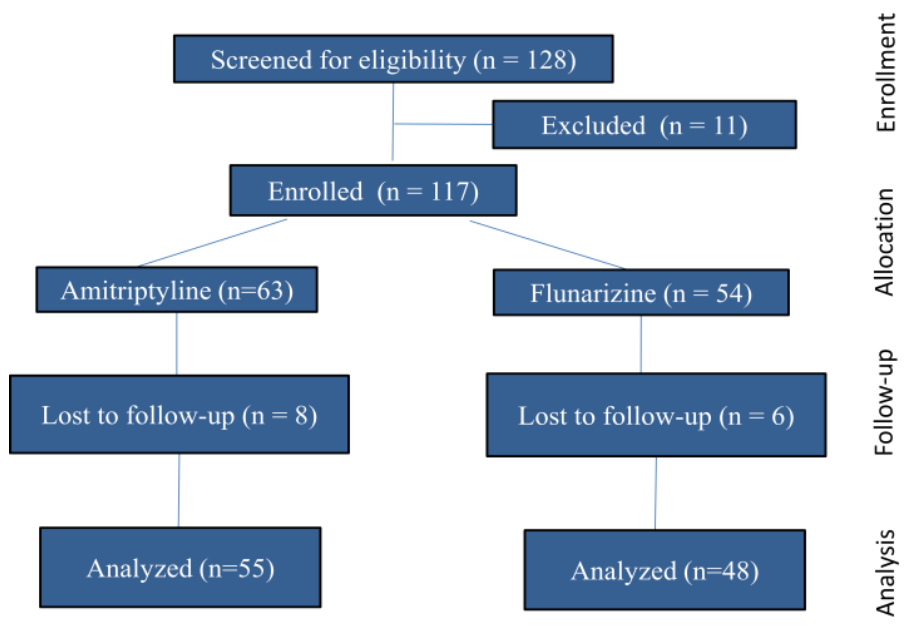

Table 1: Baseline and demographic characteristics

\begin{tabular}{|l|c|c|c|}
\hline \multicolumn{1}{|c|}{ Parameters } & Amitriptyline $(\mathbf{n = 5 5})$ & Flunarizine $(\mathbf{n = 4 8})$ & p-value \\
\hline Duration (years) & $3.75 \pm 4.4$ & $3.73 \pm 4.3$ & 0.62 \\
\hline Number of headache days (last 3 months) & $32.9 \pm 14.1$ & $35.8 \pm 16.9$ & 0.16 \\
\hline Number of episodes (last 3 months) & $26.1 \pm 12.5$ & $29.4 \pm 15.6$ & 0.10 \\
\hline Pain severity (VAS) & $8.44 \pm 1.5$ & $8.42 \pm 1.6$ & 0.74 \\
\hline MIDAS score & $15.5 \pm 8.1$ & $15.8 \pm 9.1$ & 0.95 \\
\hline HIT-6 score & $69.5 \pm 5.3$ & $69.7 \pm 4.4$ & 0.26 \\
\hline Weight (Kg) & $59.7 \pm 8.9$ & $54.1 \pm 11.1$ & 0.27 \\
\hline
\end{tabular}

Fig. 1: Age and sex distribution

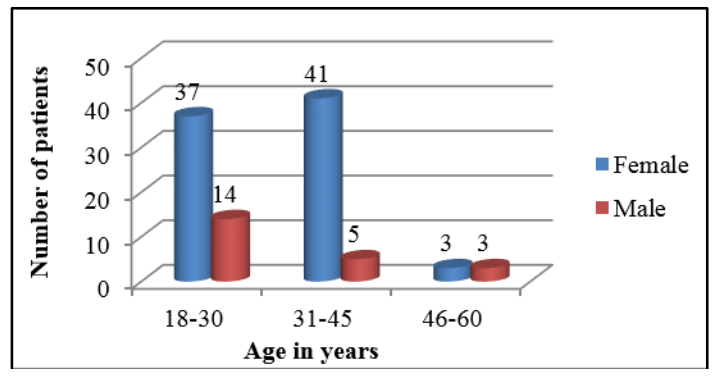

Fig. 2: Headache site

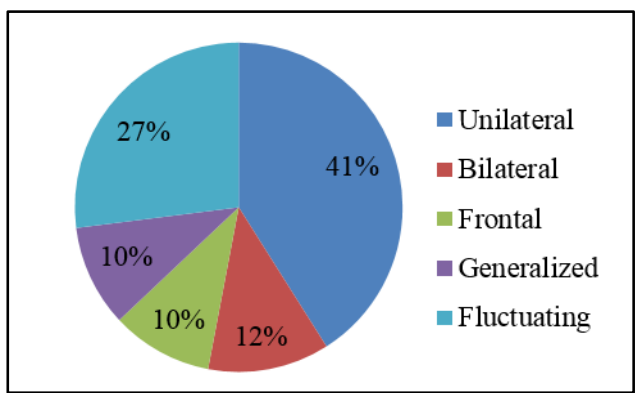




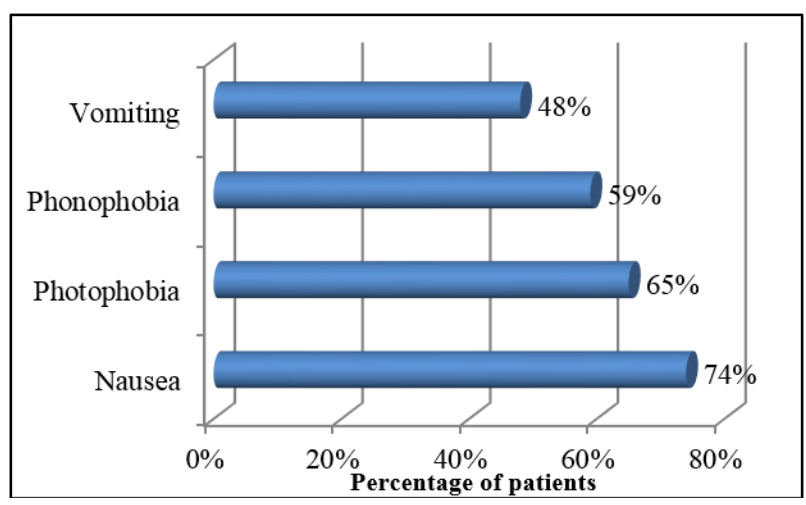

Fig. 3: Associated symptoms along with headache

Table 2: Pain severity on VAS

\begin{tabular}{|l|c|c|c|c|}
\hline & $\begin{array}{c}\text { Pain severity } \\
\text { on VAS }\end{array}$ & $\begin{array}{c}\text { Amitriptyline } \\
(\mathbf{n = 5 5})\end{array}$ & $\begin{array}{c}\text { Flunarizine } \\
(\mathbf{n = 4 8})\end{array}$ & $\begin{array}{c}\text { Total } \\
\mathbf{n}(\mathbf{\%})\end{array}$ \\
\hline Baseline & Mild & 0 & 0 & $0(0)$ \\
\cline { 2 - 5 } & Moderate & 9 & 10 & $19(18.4)$ \\
\cline { 2 - 5 } & Severe & 26 & 22 & $48(46.6)$ \\
\cline { 2 - 5 } & Worst & 20 & 16 & $36(34.9)$ \\
\hline Follow-up 1 & Mild & 4 & 3 & $7(6.7)$ \\
\cline { 2 - 5 } & Moderate & 32 & 27 & $59(57.2)$ \\
\cline { 2 - 5 } & Severe & 16 & 18 & $34(33)$ \\
\cline { 2 - 5 } & Worst & 3 & 0 & $3(2.9)$ \\
\hline Follow-up 2 & No pain & 8 & 5 & $13(12.6)$ \\
\cline { 2 - 5 } & Mild & 20 & 16 & $36(34.9)$ \\
\cline { 2 - 5 } & Moderate & 21 & 19 & $40(38.8)$ \\
\cline { 2 - 5 } & Severe & 5 & 8 & $13(12.6)$ \\
\cline { 2 - 5 } & Worst & 1 & 0 & $1(0.9)$ \\
\hline
\end{tabular}

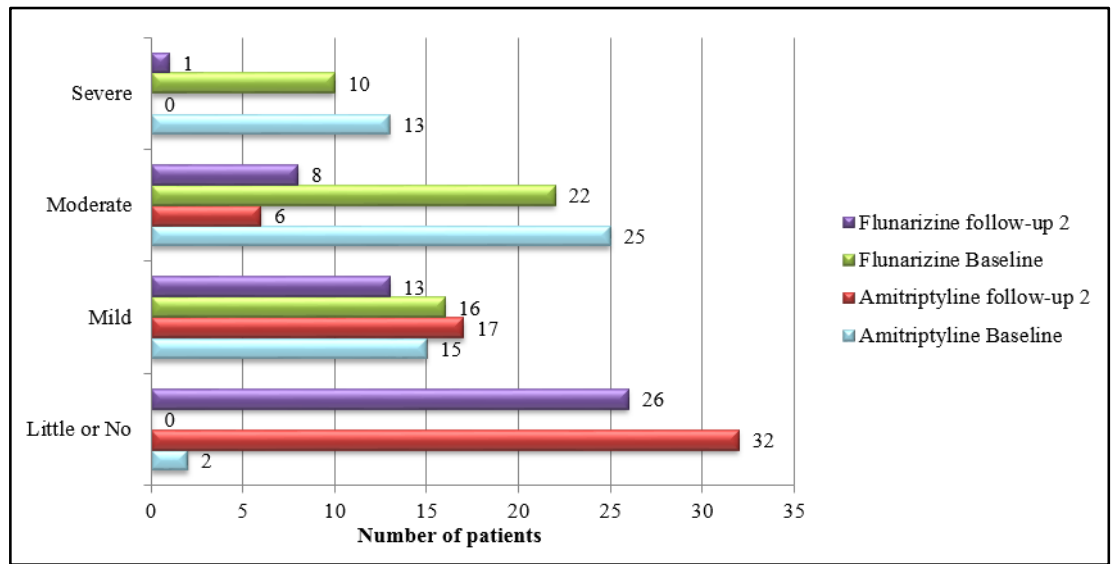

Fig. 4: MIDAS score categories 


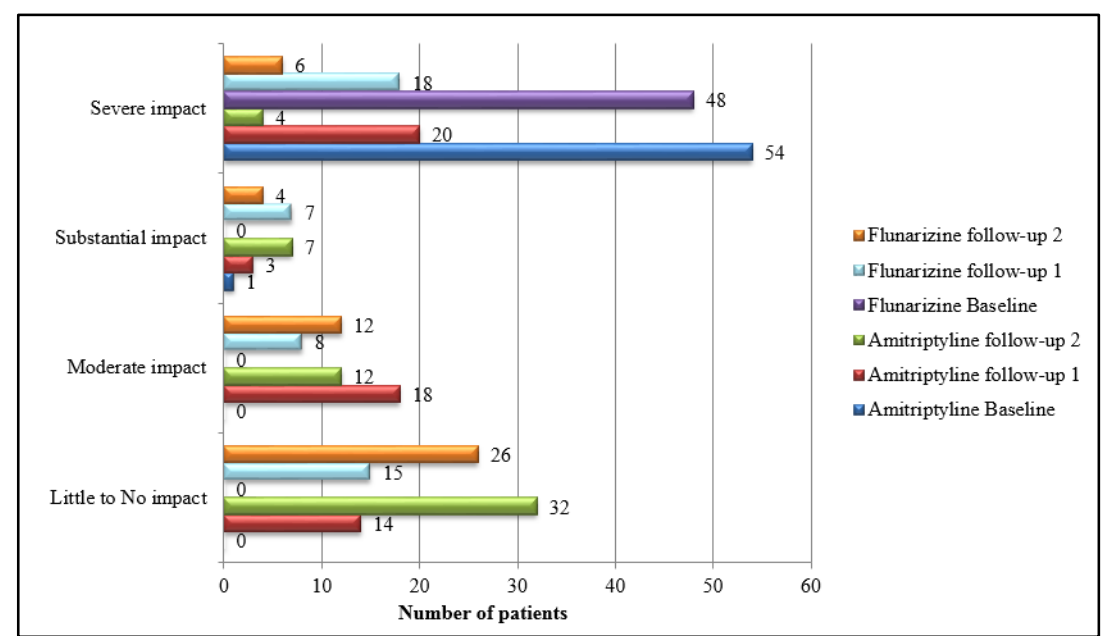

Fig. 5: HIT-6 impact test categories

Table 3: Follow-up 1 (at 1 month)

\begin{tabular}{|l|c|c|c|}
\hline \multicolumn{1}{|c|}{ Parameters } & Amitriptyline $(\mathbf{n = 5 5})$ & Flunarizine $(\mathbf{n = 4 8})$ & p-value \\
\hline Number of episodes & $7.24 \pm 4.8$ & $9.17 \pm 6.1$ & 0.11 \\
\hline Pain severity (VAS) & $5.87 \pm 2.0$ & $6.13 \pm 1.6$ & $0.04 *$ \\
\hline HIT-6 score & $56.1 \pm 9.1$ & $55.9 \pm 8.2$ & 0.22 \\
\hline Weight (Kg) & $59.7 \pm 8.9$ & $54.1 \pm 11.1$ & 0.27 \\
\hline
\end{tabular}

*Significant difference

Table 4: Follow-up 2 (at 3 months).

\begin{tabular}{|l|c|c|c|}
\hline \multicolumn{1}{|c|}{ Parameters } & Amitriptyline $(\mathbf{n = 5 5})$ & Flunarizine $(\mathbf{n}=\mathbf{4 8})$ & p-value \\
\hline Number of headache days (last 3 months) & $12.1 \pm 7.8$ & $13.9 \pm 9.5$ & 0.10 \\
\hline Number of episodes & $4.45 \pm 3.5$ & $4.69 \pm 4.3$ & 0.46 \\
\hline Pain severity (VAS) & $3.73 \pm 2.3$ & $4.02 \pm 2.1$ & 0.60 \\
\hline MIDAS score & $5.56 \pm 3.9$ & $6.42 \pm 5.1$ & 0.11 \\
\hline HIT-6 score & $48.3 \pm 7.8$ & $48.8 \pm 8.3$ & 0.60 \\
\hline Weight (Kg) & $59.6 \pm 8.8$ & $54.1 \pm 10.9$ & 0.30 \\
\hline
\end{tabular}

Table 5: Comparison of parameters within group

\begin{tabular}{|c|c|c|c|c|c|}
\hline \multirow[t]{2}{*}{ Parameters } & \multirow[t]{2}{*}{$\mathbf{A t}$} & \multicolumn{2}{|c|}{ Amitriptyline } & \multicolumn{2}{|c|}{ Flunarizine } \\
\hline & & Mean \pm SD & p-value & Mean \pm SD & p-value \\
\hline \multirow{2}{*}{$\begin{array}{l}\text { Number of days with } \\
\text { headache in last } 3 \text { months }\end{array}$} & Baseline & $32.9 \pm 14.1$ & \multirow[t]{2}{*}{0.00} & $35.8 \pm 16.9$ & \multirow[t]{2}{*}{0.00} \\
\hline & Follow-up 2 & $12.1 \pm 7.8$ & & $13.9 \pm 9.5$ & \\
\hline \multirow[t]{6}{*}{ Number of episodes } & Baseline & $26.1 \pm 12.5$ & \multirow[t]{2}{*}{0.00} & $29.4 \pm 15.6$ & \multirow[t]{2}{*}{0.00} \\
\hline & Follow-up 1 & $7.24 \pm 4.8$ & & $9.17 \pm 6.1$ & \\
\hline & Baseline & $26.1 \pm 12.5$ & \multirow[t]{2}{*}{0.00} & $29.4 \pm 15.6$ & \multirow[t]{2}{*}{0.00} \\
\hline & Follow-up 2 & $4.45 \pm 3.5$ & & $4.69 \pm 4.3$ & \\
\hline & Follow-up 1 & $7.24 \pm 4.8$ & \multirow[t]{2}{*}{0.00} & $9.17 \pm 6.1$ & \multirow[t]{2}{*}{0.00} \\
\hline & Follow-up 2 & $4.45 \pm 3.5$ & & $4.69 \pm 4.3$ & \\
\hline \multirow[t]{6}{*}{ VAS } & Baseline & $8.44 \pm 1.5$ & \multirow[t]{2}{*}{0.00} & $8.42 \pm 1.6$ & \multirow[t]{2}{*}{0.00} \\
\hline & Follow-up 1 & $5.87 \pm 2.0$ & & $6.13 \pm 1.6$ & \\
\hline & Baseline & $8.44 \pm 1.5$ & \multirow[t]{2}{*}{0.00} & $8.42 \pm 1.6$ & \multirow[t]{2}{*}{0.00} \\
\hline & Follow-up 2 & $3.73 \pm 2.3$ & & $4.02 \pm 2.1$ & \\
\hline & Follow-up 1 & $5.87 \pm 2.0$ & \multirow[t]{2}{*}{0.00} & $6.13 \pm 1.6$ & \multirow[t]{2}{*}{0.00} \\
\hline & Follow-up 2 & $3.73 \pm 2.3$ & & $4.02 \pm 2.1$ & \\
\hline \multirow[t]{2}{*}{ MIDAS } & Baseline & $15.5 \pm 8.1$ & \multirow[t]{2}{*}{0.00} & $15.8 \pm 9.1$ & \multirow[t]{2}{*}{0.00} \\
\hline & Follow-up 2 & $5.56 \pm 3.9$ & & $6.42 \pm 5.1$ & \\
\hline \multirow[t]{3}{*}{ HIT-6 } & Baseline & $69.5 \pm 5.3$ & \multirow[t]{2}{*}{0.00} & $69.7 \pm 4.4$ & \multirow[t]{2}{*}{0.00} \\
\hline & Follow-up 1 & $56.1 \pm 9.1$ & & $55.9 \pm 8.2$ & \\
\hline & Baseline & $69.5 \pm 5.3$ & 0.00 & $69.7 \pm 4.4$ & 0.00 \\
\hline
\end{tabular}




\begin{tabular}{|l|l|l|l|l|l|}
\hline & Follow-up 2 & $48.3 \pm 7.8$ & & $48.8 \pm 8.3$ & \\
\cline { 2 - 3 } & Follow-up 1 & $56.1 \pm 9.1$ & 0.00 & $55.9 \pm 8.2$ & \multirow{2}{*}{0.00} \\
\cline { 2 - 3 } & Follow-up 2 & $48.3 \pm 7.8$ & & $48.8 \pm 8.3$ & \\
\hline
\end{tabular}

Table 6: Adverse drug reactions

\begin{tabular}{|l|c|c|c|c|}
\hline & \multicolumn{2}{|c|}{ Follow-up 1 } & \multicolumn{2}{c|}{ Follow-up 2 } \\
\hline Adverse effects & $\begin{array}{c}\text { Amitriptyline } \\
(\mathbf{n = 5 5})\end{array}$ & $\begin{array}{c}\text { Flunarizine } \\
(\mathbf{n = 4 8})\end{array}$ & $\begin{array}{c}\text { Amitriptyline } \\
(\mathbf{n = 5 5})\end{array}$ & $\begin{array}{c}\text { Flunarizine } \\
(\mathbf{n = 4 8})\end{array}$ \\
\hline Dry mouth & 7 & 6 & 7 & 6 \\
\hline Dry eyes & 2 & 0 & 1 & 0 \\
\hline Bitter taste & 1 & 1 & 0 & 0 \\
\hline Constipation & 2 & 2 & 2 & 1 \\
\hline Dizziness & 2 & 0 & 1 & 1 \\
\hline Somnolence & 2 & 6 & 7 & 2 \\
\hline Abdominal pain & 1 & 0 & 0 & 1 \\
\hline Weakness & 0 & 3 & 1 & 2 \\
\hline
\end{tabular}

\section{Discussion}

Migraine is one of the common and highly disabling neurological disorders associated with a high socioeconomic burden. ${ }^{11}$ Effective prophylaxis of migraine depends on the expectations of the patients as well as the treating physicians and most physicians accept the evidence-based expectation of a 50\% reduction in attack frequency and severity. ${ }^{12}$ Therefore, the aim of appropriate prophylaxis is to improve the quality of care of patients with migraine by reducing attack frequency and severity by $50 \%$, improving functioning, productivity and thereby reducing the need for acute medication. ${ }^{12}$

The present study was a prospective, observational, comparative study, which was conducted to compare the effectiveness of flunarizine and amitriptyline in migraine prophylaxis, to assess their tolerability and to assess the disability associated with migraine before and after treatment.

A total of 103 patients (55 in the Amitriptyline group and 48 in the flunarizine group) completed the study. Majority of the patients were between 18-30 years old, which shows that migraine is more common in younger age group. There were more females (78.6\%) than males $(21.3 \%)$ in the study, which is similar to many of the previous studies where females were $\geq 70 \%$ of the study population. ${ }^{13}$

There was significant reduction in the number of episodes from baseline in amitriptyline and flunarizine groups. The percentage fall in pain score from baseline to the end of one month of treatment was slightly higher in Amitriptyline group (30.4\%) when compared to flunarizine group (27.2\%). There was a statistically significant difference in mean pain scores recorded in between the groups with p-value of 0.04 .

After three months of therapy, the frequency and severity of headaches decreased in both the groups, but there was no significant difference in between the groups. The mean reduction in the number of episodes at the end of three months compared to baseline was $84 \%$ in the flunarizine group. This was higher when compared to a study conducted by Diener $\mathrm{HC}$ et al, which showed a $53 \%$ reduction after 16 weeks of treatment with flunarizine 10 mg. ${ }^{14}$

The mean reduction in the number of episodes at the end of three months compared to baseline was $82.9 \%$ in the amitriptyline group. The fall seen in this study was greater when compared to a study which was conducted by Kalita J et al, where at three months the reduction in headache frequency from baseline was $62 \% .^{15}$

In the present study, the percentage reduction from baseline in the number of days with headache at 3 months was $63.2 \%$ in Amitriptyline group and $61.1 \%$ flunarizine group. The percentage fall in VAS score from baseline to the end of three months was slightly higher in Amitriptyline group $(55.8 \%)$ when compared to flunarizine group $(52.2 \%)$.

At three months $\geq 50 \%$ reduction in number of episodes was seen in $100 \%$ patients in Amitriptyline group, whereas, in the study conducted by Kalita $\mathrm{J}$ et al, $62 \%$ patients showed $>50 \%$ reduction in frequency at 3 months. ${ }^{15}$ In a study conducted by Dodick D et al Amitriptyline and Tompiramate were compared for migraine prophylaxis in a 26 week, multicenter, randomized, double-blind, doubledummy, parallel-group noninferiority study, and $45.9 \%$ patients experienced $\geq 50 \%$ reduction in mean monthly migraine days. ${ }^{16}$

In the flunarizine group, $\geq 50 \%$ reduction in number of episodes was seen in $95.8 \%$ patients in this study, which is higher to $61.5 \%$ patients on flunarizine at the end of treatment, in a study conducted by Luo et al. ${ }^{17}$

The overall percentage responders with $\geq 50 \%$ reduction in number of episodes of migraine and severity together were $67.3 \%$ and $50 \%$ in amitriptyline and flunarizine groups respectively. In the present study, there was also a significant reduction in the number of patients with severe and moderate disability on MIDAS score. Similarly there was a significant reduction in the number of patients with severe and substantial impact on HIT-6 score in both the treatment groups. 
The most common adverse effects seen in the Amitriptyline group were dry mouth, somnolence, constipation etc, which were similar to the study conducted by Gonçalves AL, et al, where most common adverse events were daytime sleepiness, dry mouth, epigastralgia, weight gain and constipation. ${ }^{18}$ The most common adverse effects seen in the flunarizine group were dry mouth, weakness, somnolence, dizziness and constipation, some of which like somnolence, dizziness were also seen in the study conducted by Luo et al. ${ }^{17}$ There were no serious adverse reactions in either of the study groups at any point in our study.

In the present study, there was no significant difference in the weight of the patients from baseline to three months in both the study groups unlike the study conducted by Berilgen MS et al who compared the effects of amitriptyline and flunarizine on weight gain. ${ }^{19}$ Further study for a longer duration might be helpful in understanding and establishing the effects of long term prophylactic therapy with flunarizine and amitriptyline on weight gain.

The potential limitations of this study were smaller sample size and short duration of follow-up. Another limitation was VAS scoring for pain, which is a subjective measure.

Further studies using randomized, double-blind pattern on larger sample size, multi-center, incremental doses, for a longer duration are recommended to establish a definitive conclusion of the effectiveness and tolerability of these drugs.

\section{Conclusion}

Based on the observations made in this study, it can be concluded that both Amitriptyline and Flunarizine are effective in prophylaxis of migraine, however, Amitriptyline has a higher overall responder rate when compared to Flunarizine, with almost similar tolerability profile.

\section{Acknowledgement}

I would like to extend my sincere thanks to the Professor and Head of the department of Pharmacology, Head of the department of Psychiatry, teaching staff, non teaching staff, colleagues of department of pharmacology and psychiatry for their continuous support, and all the patients who participated in the study.

\section{Conflict of Interest: None.}

\section{References}

1. Headache disorders. Fact-sheet: Updated April 2016. Available from: http://www.who.int/mediacentre/factsheets/fs277/en/ Accessed on 25-07-18.

2. Martelletti P, Birbeck G, Katsarava Z, Jensen R, Stovner L, Steiner T. The Global Burden of Disease survey 2010, Lifting the Burden and thinking outside-the-box on headache disorders. J Headache Pain. 2013;14(1):13.

3. Steiner T, Stovner L, Birbeck G. Migraine: the seventh disabler. J Headache Pain. 2013;14(1):1.

4. Kasper DL, Fauci AS, Hauser SL, Longo DL, Jameson JL, Loscalzo J, eds. Harrison's principles of internal medicine. $19^{\text {th }}$ ed. New York: The McGraw-Hill;2015. p.2590.
5. Minton G, Miller A, Bookstaver B, Love B. Topiramate: Safety and efficacy of its use in the prevention and treatment of migraine. J Cent Nerv Syst Dis. 2011;3:155-168.

6. Bartleson J, Cutrer F. Migraine update. Diagnosis and treatment. Minn Med. 2010;93(5):36-41.

7. Rahimdel A, Zeinali A, Yazdian-anari P, Hajizadeh R, Arefnia E. Effectiveness of Vitamin B2 versus Sodium Valproate in Migraine Prophylaxis: a randomized clinical trial. Electron Physician. 2015;7(6):1344-1348.

8. Evers S, Afra J, Frese A, Goadsby P, Linde M, May A. EFNS guideline on the drug treatment of migraine - revised report of an EFNS task force. Eur J Neurol. 2009;16(9):968-981.

9. Stewart WF, Lipton RB, Kolodner KB, Sawyer J, Lee C, Liberman JN. Validity of the Migraine Disability Assessment (MIDAS) score in comparison to a diary-based measure in a population sample of migraine sufferers. Pain. 2000;88(1):41-52.

10. Juyal R, Verma R, Garg RK, Shukla R, Agarwal A, Singh MK Reliability and validity of Hindi translation of the migraine disability assessment and headache impact test-6 questionnaires. Ann Indian Acad Neurol. 2010;13(4):276-283.

11. Antonaci F, Ghiotto N, Wu S, Pucci E, Costa A. Recent advances in migraine therapy. Springer Plus. 2016;5:637.

12. Dekker F, Neven AK, Andriesse B, Kernick D, Ferrari MD, Assendelft WJ. Prophylactic treatment of migraine by GPs: a qualitative study. Br J Gen Pract. 2012;62(597):268-274.

13. Jackson JL, Cogbill E, Santana-Davila R, Eldredge C, Collier W, Gradall A, et al. A Comparative Effectiveness MetaAnalysis of Drugs for the Prophylaxis of Migraine Headache. PLoS ONE. 2015;10(7):1-60.

14. Diener HC, Matias-Guiu J, Hartung E, Pfaffenrath V, Ludin HP, Nappi G, et al. Efficacy and tolerability in migraine prophylaxis of flunarizine in reduced doses: a comparison with propranolol $160 \mathrm{mg}$ daily. Cephalagia. 2002;22:209-221.

15. Kalita J, Bhoi SK, Misra UK. Amytriptyline vs Divalproate in migraine prophylaxis: a randomized controlled trial. Acta Neurol Scand. 2013;128(1):65-72.

16. Dodick DW, Freitag F, Banks J, Saper J, Xiang J, Rupnow M et al. Topiramate versus amitriptyline in migraine prevention: a 26-week, multicenter, randomized, double-blind, doubledummy, parallel-group noninferiority trial in adult migraineurs. Clin Ther. 2009;31(3):542-559.

17. Luo N, Di W, Zhang A, Wang Y, Ding M, Qi W. A randomized, one-year clinical trial comparing the efficacy of topiramate, flunarizine, and a combination of flunarizine and topiramate in migraine prophylaxis. Pain Med. 2012;13(1):8086.

18. Gonçalves AL, Ferreira AM, Ribeiro RT, Zukerman E, Cipolla-Neto J, Peres MF. Randomised clinical trial comparing melatonin $3 \mathrm{mg}$, amitriptyline $25 \mathrm{mg}$ and placebo for migraine prevention. J Neurol Neurosurg Psychiatry. 2016;87(10):11271132.

19. Berilgen MS, Bulut S, Gonen M, Tekatas A, Dag E, Mungen B. Comparison of the effects of amitriptyline and flunarizine on weight gain and serum leptin, $C$ peptide and insulin levels when used as migraine preventive treatment. Cephalalgia. 2005;25(11):1048-1053.

How to cite this article: Bhavani $\mathrm{V}$, Nagabushan $\mathrm{H}$, Bhagyavathi H. D. Oral flunarizine versus oral amitriptyline in migraine prophylaxis - A prospective open label study. Indian $\mathrm{J}$ Pharm Pharmacol. 2018;5(4):179-186. 